\title{
García Lorca y la lírica popular. Una propuesta para la E.S.O.
}

\author{
Adriana GÓMEZ DÍAZ \\ Universidad Complutense de Madrid \\ Departamento de Didáctica de la Lengua y la Literatura \\ adriana.gomez.diaz@estumail.ucm.es
}

Recibido: junio 2012

Aceptado: enero 2013

\section{RESUMEN}

El documento presentado a continuación tiene como finalidad proporcionar una innovación educativa en Secundaria Obligatoria, que afecta al área de Lengua y Literatura. Para ello, se va a tratar el tema de la enseñanza de la lírica popular a través de Federico García Lorca. Así, tras llevar a cabo una breve introducción teórica sobre el tema, se proporciona una propuesta educativa, en la que se ejemplifica la manera en que este tema podría llevarse a cabo en el aula, consiguiendo una enseñanza no solo innovadora, sino también necesaria para la formación de los estudiantes.

Palabras clave: Lírica popular, García Lorca, Educación Secundaria Obligatoria, innovación educativa.

\section{García lorca and the popular poetry. A proposal for Compulsory Secondary Education}

\section{ABSTRACT}

The aim of this paper is to provide for educational innovation in Compulsory Secondary Education involving the subject of Spanish Language and Literature. In order to do so, the topic of teaching popular poetry by using Federico García Lorca's works will be dealt with. Therefore, after carrying out a brief theoretical introduction on the topic, an educational proposal is provided, in which the possible way to implement it in the classroom is exemplified, thus achieving both innovative and essential teaching for the students' education. Keywords: Popular poetry, García Lorca, Compulsory Secondary Education, educational innovation.

\section{García Lorca et la lyrique populaire. Une proposition pour l'Éducation Se- condaire Obligatoire} RESUMÉ

Le document présenté ci-dessous a comme finalité celle de procurer une innovation éducative en Éducation Secondaire Obligatoire qui touche le domaine de la Langue et la Littérature. Pour y aboutir, on abordera le sujet de l'enseignement de la lyrique populaire à travers Federico García Lorca. Ainsi, après avoir effectué une brève introduction théorique à propos du sujet, on fournira une proposition éducative où l'on exemplifiera la façon où tel sujet pourrait être abordé en classe, tout en obtenant un enseignement innovateur mais aussi nécessaire pour la formation des étudiants. 
Mots clé: Lyrique populaire, García Lorca, Éducation Secondaire Obligatoire, innovation éducative.

SUMARIO: 1. Introducción. 2. El porqué de la obra de Federico García Lorca. 3. Propuesta educativa. 3.1. Actividades para $2^{\circ}$ E.S.O. 3.1.1. Actividad (1). 3.1.2. Actividad (2). 3.1.3. Actividad (3) 3.1.4. Actividad (4) 3.1.5 Actividad (5) Opcional. Atención a la diversidad 3.2. Actividades para $4^{\circ}$ E.S.O. 3.2.1. Actividad (1) 3.2.2. Actividad (2) 3.2.3. Actividad (3) 3.2.4.Actividad (4) 3.2.5. Actividad (5). Opcional. Atención a la diversidad 4. Conclusiones. 5. Referencias bibliográficas.

\section{INTRODUCCIÓN}

La lírica suele estar ligada generalmente a la tradición oral. A través de estos poemas que circulan en forma de canciones, villancicos, canciones infantiles, etc. se puede conocer la conciencia colectiva de los hablantes de una lengua. De este modo, conforma uno de los géneros más antiguos de la literatura que, como consecuencia, ha influido notablemente en las producciones literarias de todos los tiempos.

El objetivo principal que persigue esta innovación es que los alumnos de la E.S.O. conozcan esa tradición literaria española a través de dos vertientes: por una parte, mediante romances y canciones recogidos por el propio Lorca y, por otra parte, con la presencia de elementos del folclore andaluz que marcan parte de la obra poética del autor.

Actualmente la lírica popular no ocupa un lugar relevante en las diferentes etapas educativas, de manera que si bien en algunos centros escolares los niños de primaria aprenden alguna canción o poema, desconocen su función; como consecuencia es bastante probable que con el tiempo se olvide, o si se recuerda no se sepa que pertenece a este tipo de lírica. En Secundaria, suele mencionarse la importancia que esta tradición ejerce sobre algunos escritores, sin embargo, no se explica en qué consiste dicha literatura popular, ni se muestran ejemplos claros, exceptuando algunos ligados a la Edad Media, escritos en castellano antiguo, lo cual provoca que el estudiante muestre un desinterés notable, en tanto que no lo percibe como algo próximo. De este modo, los alumnos finalizan sus estudios sin conocer las bases fundamentales en las que se apoyan las letras españolas. Todo ello hace que, generación tras generación, se vaya perdiendo y olvidando esta lírica; y no solo eso, sino que tampoco se reconocen las formas básicas en que se componen.

Existen dos factores por el que resulta interesante trabajar este tipo de poesía.

En primer lugar, por la pérdida que la lírica popular está teniendo hoy en día, el hecho de que los jóvenes no conozcan rasgos mínimos de lo que define a una sociedad a lo largo de su historia, es un error. La literatura durante muchos siglos ha estado basada en este tipo de lírica, por lo que tanto alumnos españoles como extranjeros deberían conocerla antes de finalizar sus estudios.

En segundo lugar, la poesía es quizás el género literario que peor cala en la juventud, bien porque no la entienden, bien porque es considerada muy sentimental. 
Sin embargo, la música es un arte muy apreciado por los adolescentes y el hecho de que lírica popular y canción estén estrechamente unidas aporta una herramienta muy buena de trabajo para el docente. Así, puede llevarse a cabo un estudio multidisciplinar en donde el profesor de literatura junto con el de música elaboren actividades de doble orden: que fomenten la enseñanza - aprendizaje y que lleven consigo un componente lúdico y motivador. Este tipo de proyecto, en que se combinan dos artes en la enseñanza, beneficia no solo al alumno que se encuentra sumergido en una nueva metodología que amplía sus conocimientos, siendo capaz de relacionar varios aspectos culturales, sino que el equipo docente siente la obligación y necesidad de recurrir a otros especialistas, lo cual fomenta el trabajo en equipo.

Quizás una de las causas que provocan el fracaso escolar sea precisamente la escasa o nula relación que los estudiantes son capaces de establecer entre diferentes campos de conocimiento. La poca capacidad de reflexión y crítica muchas veces viene producida por esa falta de información que el arte en sí mismo aporta a la sociedad. Por otra parte, es el modo ideal de acercar el arte a los centros escolares y de que este deje de ser visto como algo antiguo, ajeno a los jóvenes.

Cuando reconocen una canción y descubren que detrás de la misma se esconde un poema o viceversa, son conscientes de que aún la cultura artística mueve a sociedades enteras y de que la literatura llega a ámbitos más alejados del libro material. En definitiva, los docentes encuentran nuevas herramientas de trabajo distintas al libro para acercar la literatura al alumno, para completar y ensanchar los conocimientos. Es más, descubren maneras que pueden despertar la curiosidad, intriga o gusto por lo que miles de poemas llevan escrito en sus páginas, sobre todo cuando el amor por la cultura de todos los tiempos se está perdiendo en una sociedad cada vez más digitalizada.

Aparte de la ampliación de conocimientos, la mejor relación que se va a poder establecer entre elementos literarios y el estudio multidisciplinar, hay otros aspectos que también afectan positivamente al estudiante y a la armonía escolar.

Por una parte, el conocimiento de la lírica popular permite a los alumnos interesarse por las costumbres y tradiciones de su entorno. Se produce un ensanchamiento cultural que ayuda a comprender aspectos de la vida cotidiana y a entender la identidad de su nación. Además, el hecho de que España se haya convertido en un país de fuerte atracción migratoria hace necesario que el conocimiento de las culturas se expanda. No hay que olvidar que la buena adaptación a otra cultura y país comienza con el conocimiento de sus costumbres, leyes y cultura en general. Así, los estudiantes inmigrantes podrán insertarse mejor en la cultura española conociendo alguna de las tradiciones como lo es la poesía popular, la cual descubre las vivencias de todo un pueblo a lo largo de su historia. Por lo tanto, si a través de la enseñanza de la literatura también se cubren otros aprendizajes, en este caso sociales, la educación tendrá sentido en su totalidad. 
Otro de los beneficios es la actividad mental y psicológica que los estudiantes realizan al retener parte del poema o de la canción. Como consecuencia, es portadora de valores lingüísticos y literarios como las rimas, las aliteraciones, los juegos de palabras, las metáforas sencillas, construcciones gramaticales sencillas, estribillos, etc., las cuales pueden contribuir al desarrollo creativo de la expresividad, fomentar habilidades poéticas y crear sólidos lectores.

\section{EL PORQUÉ DE LA OBRA DE FEDERICO GARCÍA LORCA}

Al hablar de un escritor como García Lorca se ha recurrido a afirmar que en él se mezclan tradición y vanguardia. Resulta imposible no recurrir a la lírica tradicional cuando se intenta entender y reflexionar sobre su obra.

Nacido en la provincia de Granada, Lorca se preocupó, no solo del entorno que lo rodeaba, sino del ser humano. Quizás, debería añadirse que las personas a las que hace referencia, como las mujeres, los gitanos o los negros, son seres marginados con los que el artista se identifica. Sin embargo, cualquier persona puede sentirse identificada con las palabras del escritor. En términos generales, es el artista de todo un pueblo. José Luis Cano, 1962, citado por Allen Josephs y Juan Caballero $(2009,79)$ realiza una afirmación sobre el Romancero gitano la cual confirma lo dicho hasta este momento:

Raramente un libro de poesía logra obtener, como lo obtuvo este libro de Federico, un éxito popular y al mismo tiempo la admiración de los críticos más selectos. En este caso, mayoría y minoría coincidían en admirar unos romances en los que la maravillosa fantasía del poeta, sus palabras sabias y misteriosas - con la sabiduría y el misterio de la milenaria Andalucía -, habían logrado calar y conmover el alma del pueblo, del suyo, el andaluz, y el de toda España.

Además, partiendo de su poesía se han elaborado diversos poemarios destinados a niños. Ello se debe a que Lorca nunca quiso eliminar esta primera etapa de su vida en tanto que era muy importante para el poeta no desligarse definitivamente del mundo de la infancia, por cuanto su propia poesía ha nacido de la canción infantil y teme perder su condición de poeta, si deja por completo de ser niño. Para el autor la figura del niño es muy relevante en la literatura tradicional, ya que es este el depositario por excelencia de la que fue poesía y canción popular, patrimonio de todo un pueblo.

Es importante mencionar que gran parte de la tradición literaria popular recogida por Lorca se encuentra en forma de canciones populares. En 1928 el poeta, citado en Rodríguez $(2010,69)$ confirmó que:

la melodía, mucho más que el texto, define los caracteres geográficos y la línea histórica de una región /.../ Un romance, desde luego, no es perfecto hasta que no lleva su propia melodía, que le da sangre y la palpitación y el aire severo o erótico donde se mueven los personajes. 
En este sentido, cabe destacar que Lorca antes que poeta, fue músico. La música es un elemento que va a estar presente a lo largo de toda su vida y como consecuencia, en su obra.

Antes de comenzar sus estudios de piano con Antonio Segura Mesa, la música popular andaluza ya formaba parte de su vida cotidiana, siendo este niño. José Luis Cano, 1962, citado por Josephs y Caballero $(2009,58)$ lo expresa así:

Aquellas veladas musicales, por muy modestas que fuesen, debieron de ser una fiesta grande que embriagaba sus sentidos, y sobre todo el sentido del oído, tan vivo en él desde su infancia. En aquellas veladas familiares, en que se tocaban y cantaban aires populares, y en su pasión precoz por el teatro, hay que buscar la raíz de su arte de poeta y de dramaturgo, de maravilloso juglar moderno.

Más adelante, como consecuencia de ese conocimiento lirico-musical recibido en su infancia y la preocupación por mantener viva la tradición oral, Lorca decidió estudiar y recoger las colecciones de canciones y romances populares de toda España, publicadas por los folcloristas e investigadores. El Cancionero popular español, de Felipe Pedrell; el Cancionero de Salamanca, de Dámaso Ledesma; el Cancionero de Burgos, de Federico Olmeda; el Cancionero de Asturias, de Eduardo Martínez Torner; el Cancionero andaluz, de Eduardo Ocón; y el Cancionero de Palacio, o el de Upsala no tendrán secreto para García Lorca.

Este gusto lorquiano por lo popular y, en especial por lo tradicional andaluz, va a verse incrementado a raíz de su amistad con Manuel de Falla. Es a partir de ese momento, 1920, cuando la música folclórica andaluza va a calar más hondo aún si cabe, en el poeta. Así, en 1922 se celebra en Granada un festival de cante jondo. Esta reunión vino propiciada por la preocupación de ambos artistas, junto con la de otros, por la decadencia que estaba sufriendo el género; quisieron demostrar que este cante no era solo una supervivencia de tiempos pasados sino una belleza artística a la que había que tomar en serio como expresión típica del folclore nacional.

A lo largo de su creación artística, García Lorca va a intentar conservar y dignificar este cante jondo. Verdaderamente, el granadino lo conservó, no solo con su obra literaria, especialmente con su Poema del cante jondo y el Romancero gitano, sino armonizando una docena larga de esos cantos y romances españoles recogidos en los cancioneros.

\section{PROPUESTA EDUCATIVA}

La propuesta educativa que se desarrolla va dirigida a alumnos de Secundaria Obligatoria, fundamentalmente a estudiantes de $2^{\circ}$ E.S.O y $4^{\circ}$ E.S.O. La elección 
de los cursos depende de los contenidos que en ambos se debe desarrollar según el Boletín Oficial de Educación de la Comunidad de Madrid $^{1}$

En $2^{\circ}$ E.S.O. el aprendizaje de la lírica se desenvuelve de un modo más general, lo cual favorece la libertad para escoger poemas e incluirse la poesía popular como testimonio literario. Además, en este curso, las lecturas suelen estar marcadas por autores de la generación del 98 o la generación del 27 ya que comienza a estudiarse esta etapa literaria. Así, en $4^{\circ}$ E.S.O. los contenidos se vuelven más específicos y se retoman dichos movimientos literarios con el fin de un aprendizaje más profundo, tanto de las características generacionales como de los autores.

Para la E.S.O las actividades deben suponer un mayor dinamismo y participación del alumnado. Hay que tener en cuenta que muchos alumnos comienzan a sentirse atraídos por aspectos ajenos a los estudios, quedando estos en un puesto secundario. Además, algunos se sentirán forzados a estudiar ya que encuentran en el ámbito laboral una mayor atracción, de hecho, muchos no proseguirán sus estudios una vez finalizada la Secundaria Obligatoria. Todo ello hace que la desmotivación pueda ser mayor.

Otro factor que condiciona la desmotivación es la repetición de temario. El hecho de que año tras año se estudien los mismos contenidos, del mismo modo, hace que el aburrimiento se apodere de los jóvenes. Por ello, es misión del docente conseguir que los temas nunca sean estudiados de la misma forma, que en cada curso se descubran nuevos elementos que agranden el mundo intelectual de los estudiantes. Precisamente por esto, se ha dividido esta innovación en dos cursos distintos en donde el temario se repite. La división está basada en relación con la capacidad de abstracción del estudiante y su formación intelectual. Así, durante $2^{\circ}$ E.S.O. lo que se pretenderá es que los estudiantes se familiaricen con la lírica popular creada por el pueblo, es decir, que sean conscientes de los poemas y canciones que se han elaborado a lo largo de los años, los cuales Lorca se encargó de recoger y armonizar. Cuando estas nociones hayan sido recogidas por los alumnos, más adelante, en $4^{\circ}$ E.S.O. se continuará con el estudio de esta lírica popular pero concentrada en la obra del poeta, es decir, se estudiarán los elementos de la poesía popular y del folclore que aparecen en la poesía de Federico García Lorca.

El tipo de actividades que se proponen intentan partir de un estilo de enseñanza activo, en el que la participación del alumno y el trabajo colaborativo para la construcción de su propio conocimiento, jueguen un papel central. Además, se intenta facilitar la interacción, no solo entre alumnos, sino también con el profesor. Es imprescindible fomentar la construcción de aprendizajes significativos y mostrar la

${ }^{1}$ B.O.C.M. Núm.126. DECRETO 23/2007, de 10 de mayo, del Consejo de Gobierno, por el que se establece para la Comunidad de Madrid el currículo de la Educación Secundaria Obligatoria. 
funcionalidad de los mismos partiendo de los conocimientos de los alumnos para la adquisición de nuevos contenidos.

En el diseño de las actividades se va a tener en cuenta la claridad y se evitará la monotonía, en tanto que deben ser motivadoras. Es importante que las actividades sigan una gradación de dificultad, así se comenzará por lo más sencillo y básico para ir progresando en dificultad. Es evidente que deberán alcanzar los objetivos propuestos y que tendrán relación con los contenidos.

En relación a la atención a la diversidad, se tendrá especial cuidado con los alumnos extranjeros ya que no se intenta que se vean sometidos o presionados a aceptar dichas tradiciones españolas, sino solo a que las conozcan para que su inserción social sea más rápida y que, culturalmente, posean un conocimiento de la sociedad donde viven. De este modo, para que se sientan cómodos, se realizará alguna actividad dirigida a ellos y a su cultura, en tanto que, este proyecto permite no únicamente conocer mejor el mundo artístico español, sino que da la oportunidad de compartir culturas y tradiciones distintas.

\subsection{Actividades para $2^{\circ}$ E.S.O.}

El objetivo principal que se intentará conseguir es que los alumnos conozcan la lírica popular española con alguna de sus características, no sólo medieval, sino la de todos los tiempos, aquella que ha influido tanto en escritores nacionales como García Lorca. Para ello, el material básico será la Colección de canciones populares².

\subsubsection{Actividad (1)}

La lírica popular expresa los sentimientos de un pueblo. Es lo que en muchas películas se quiere reflejar cuando se pone en boca de los protagonistas una serie de canciones. De acuerdo con esto, lee los siguientes poemas y escoge los dos que más te gusten. Con ellos, deberás crear un breve argumento.

\author{
EN EL CAFÉ DE CHINITAS \\ En el café de Chinitas \\ dijo Paquiro a su hermano: \\ Soy más valiente que tú, \\ más torero y más gitano. \\ Sacó Paquiro el reló \\ y dijo de esta manera: \\ Este toro ha de morir \\ antes de las cuatro y media. \\ $\mathrm{Al}$ dar las cuatro en la calle \\ se salieron del café \\ y era Paquiro en la calle \\ un torero de cartel.
}

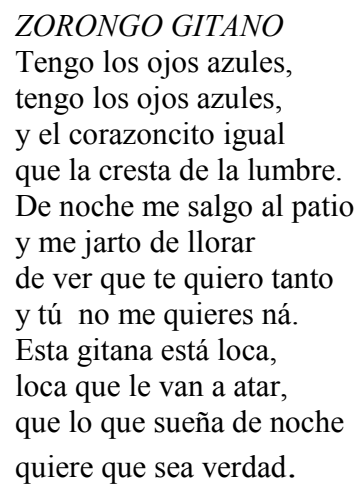

${ }^{2}$ Conjunto de canciones que el poeta grabó con la Argentinita para la firma La Voz de su Amo y editadas en discos gramofónicos en 1931. 


\author{
LAS MORILLAS DE JAÉN \\ Tres morillas me enamoran \\ en Jaén: \\ Axa,y Fátima y Marién. \\ Tres moricas tan lozanas, \\ iban a coger manzanas \\ en Jaén: \\ Axa,y Fátima y Marién. \\ Díjeles: ¿Quién sois, señoras, \\ de mi vida robadoras? \\ Cristianas que éramos moras \\ en Jaén: \\ Axa,y Fátima y Marién.
}

\author{
Tres morillas me enamoran \\ en Jaén: \\ Axa y Fátima y Marién. \\ Tres morillas tan garridas \\ iban a coger olivas, \\ y hallánbalas cogidas \\ y tornaban desmaídas \\ en Jaén: \\ Axa y Fátima y Marién.
}

Objetivo: Familiarizarse con la lírica española. Conocer algunos temas y contextos que podrían darse para la formación de estos poemas.

Metodología: Los alumnos escucharán y leerán las canciones populares que se han expuesto. Luego, en parejas, deberán escoger dos de ellas y crear un pequeño argumento cinematográfico en donde puedan emplearse, es decir, imaginar que esa canción es parte de la banda sonora de una película. Finalmente, se expondrán en voz alta.

Materiales: Fotocopias que el docente entregará con los poemas escogidos, el material del alumno (cuaderno de clase) y el CD con altavoces para escuchar la versión original.

Evaluación: Se tendrá en cuenta el trabajo colaborativo y la capacidad creadora de los alumnos.

\subsubsection{Actividad (2)}

Como continuación de la actividad anterior, deberéis poner música a aquel poema que más os guste según la situación y, como consecuencia, con la sensación que os haya transmitido.

Objetivo: Conocer la relación que ambas artes, música y literatura, guardan, en cuanto a ritmo y rima se refiere. Ser conscientes de la correspondencia que debe establecerse entre sonidos y letras para expresar correctamente un sentimiento

Metodología: De los poemas escogidos por cada pareja, seleccionarán uno que deberá ser musicado por ellos, según la sensación que les transmita la letra y según el contexto en que lo hayan situado. Para ello, tanto el docente de literatura como el de música deberán explicar los tipos de rima y los tipos de ritmo existentes, así como comentar qué rima concuerda mejor con qué ritmo.

Materiales: Empleo de los ordenadores de la sala de informática del centro. Se necesitará la instalación de programas informáticos como Audacity o Sibelius, especializados en creación de sonidos. Para ello será necesaria la colaboración del profesor de música; creándose de este modo una actividad de carácter interdisciplinar. 
Evaluación: Se evaluará el trabajo colaborativo del alumno/a y la capacidad que este muestra para relacionar letra con música.

\subsubsection{Actividad (3)}

En grupos, completad los espacios vacíos del poema con una o varias palabras, según creáis más conveniente. A continuación, intercambiad la hoja con el grupo de al lado y jugad con los miembros de vuestro grupo al teléfono descacharrado, apuntando en el cuaderno lo que el último entienda.

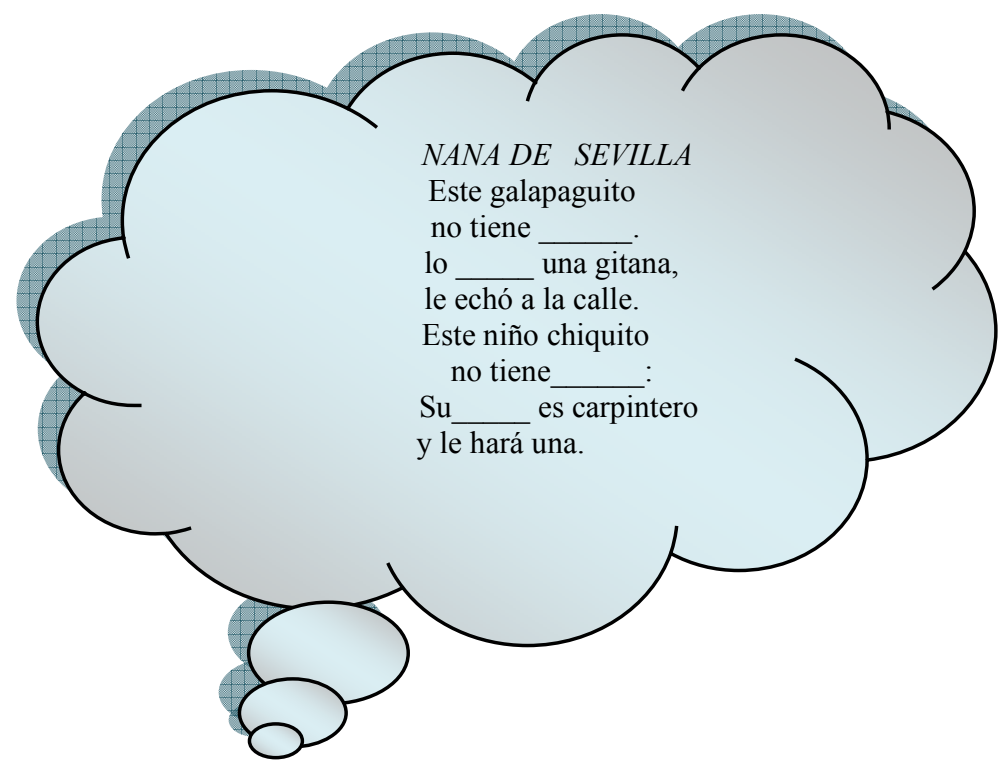

Dibujo con contenido de texto poético: Nana de Sevilla.

Objetivo: Conocer, aproximadamente, el proceso en que surgen las variantes de la lírica popular.

Metodología: En grupos, se dará el texto que se ha presentado, el cual está incompleto. Se trata de que los alumnos rellenen los espacios libres con la palabra o palabras que crean más convenientes. Luego se intercambiarán los papeles entre los grupos y, simulando el juego del teléfono descacharrado, los componentes de cada grupo tendrán que ir diciéndose uno a otro (verso por verso) lo que pone en la hoja. A continuación, leerán en voz alta aquel que se les dio y lo que el último alumno de cada grupo ha entendido. Para terminar, se escuchará la canción original para que conozcan el poema real y comparen con su creación.

Materiales: Fotocopia proporcionada por el docente donde aparece el poema incompleto. Material individual de los alumnos (cuaderno). CD y altavoces para escuchar la versión original.

Evaluación: El alumno/a entiende el concepto de variante. 


\subsubsection{Actividad (4)}

Memoriza uno de estos poemas y sé el primero de tu grupo en recitarlo cuando suene la música.

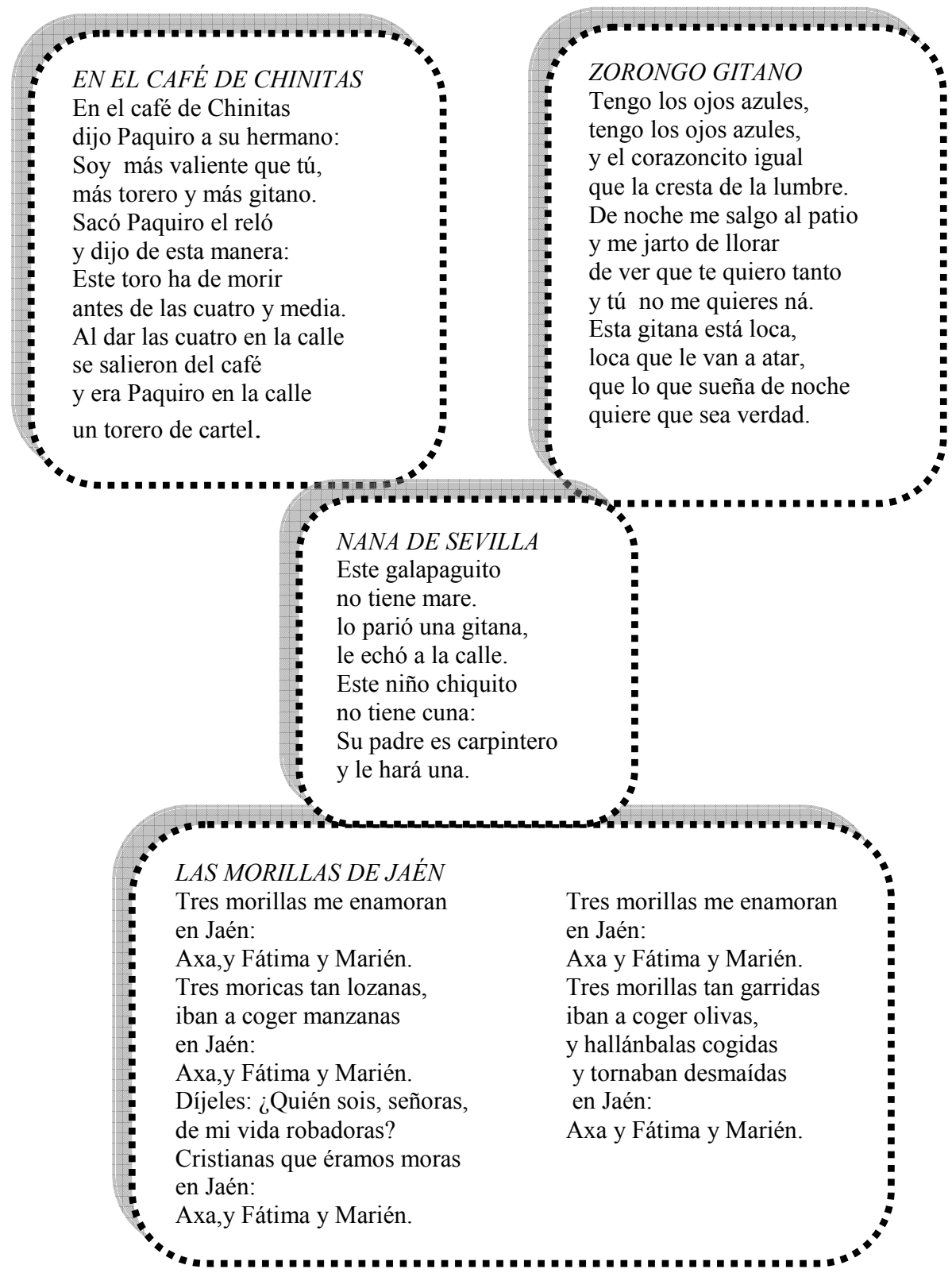

Texto poético: Las morillas de Jaén 
Objetivo: Agilizar la mente a través de la memorización. Ser consciente de cómo un poema resulta más sencillo de memorizar cuando posee melodía.

Metodología: En grupos de cuatro componentes, cada alumno memorizará uno de los poemas que se han trabajado en clase: Zorongo gitano, En el Café de Chinitas, Las morillas de Jaén y la Nana de Sevilla. Días después, los alumnos se reunirán con su grupo y el profesor pondrá la canción. La persona que sepa cuál es, se pondrá de pie y recitará la letra. El primero en levantarse y decir bien la letra obtendrá punto para su equipo. Después, el resto de compañeros que tenían el mismo poema también lo recitará pero sin obtener ese punto.

Materiales: Fotocopias por parte del docente de los poemas tal y como deben memorizarse. CD y altavoces para escuchar las canciones. Además, el profesor proporcionará las siguientes webs donde los alumnos pueden encontrar la música para que el proceso de memorización sea más sencillo. Estas muestran la versión de Lorca con la Argentinita, sin embargo, se dará libertad para que busquen cualquier otra versión.

Nana de Sevilla $\quad$ http://www.youtube.com/watch?v=rPScsaW0RYk

Café de Chinitas http://www.youtube.com/watch?v=EQLSwW3ilFQ

Zorongo gitano http://www.youtube.com/watch?v=fyTMLieOP20

Tres morillas de Jaén http://www.youtube.com/watch?v=MLiK8NtQElc

Evaluación: El alumno ha memorizado y recitado correctamente el poema.

\subsubsection{Actividad (5) - Opcional - Atención a la diversidad}

Busca un poema de composición popular de tu país y muéstralo a tus compañeros. Señala en él los rasgos característicos de tu cultura.

Objetivo: Atender a la diversidad de alumnos extranjeros. Dar a conocer cómo cada pueblo ha creado sus composiciones partiendo de su propia historia y características.

Metodología: Cada alumno extranjero, opcionalmente, buscará algún ejemplo de lírica popular de su nación y lo mostrará en clase. Los demás alumnos participarán mencionando diferencias y similitudes que encuentren con la lírica tradicional española.

Materiales: Los proporcionados por el alumno extranjero.

Evaluación: Se valorará positivamente la participación del alumno.

\subsection{Actividades para $4^{\circ}$ E.S.O.}

El objetivo principal que se persigue en este curso es que los alumnos sigan descubriendo el mundo de la lírica popular española pero esta vez en la obra de Federico García Lorca. Es decir, estudiar qué elementos de lo tradicional y del folclore están presentes en la obra del artista.

El material con el cual se va a trabajar es El Poema del cante jondo y El Romancero gitano. De ambos libros solo se seleccionarán secciones o poemas rele- 
vantes en donde los rasgos populares estén claros y completen las explicaciones que adentrarán en las actividades.

\subsubsection{Actividad (1)}

Dentro del poemario Poema del Cante jondo de García Lorca se encuentra la sección Poema de la siguiriya gitana. En este, el poeta intenta construir verbalmente la composición musical de la siguiriya. Lee los poemas y siguiendo lo descrito por el poeta construye, a través de sonidos, la composición musical.

\section{EL PASO DE LA SEGUIRIYA.}

Entre mariposas negras, va una muchacha morena junto a una blanca serpiente de niebla.

Tierra de luz, cielo de tierra.

Va encadenada al temblor de un ritmo que nunca llega; tiene el corazón de plata y un puñal en la diestra. ¿Adónde vas, siguiriya con un ritmo sin cabeza? ¿Qué luna recogerá tu dolor de cal y adelfa?

Tierra de luz, cielo de tierra.

\section{EL GRITO}

La elipse de un grito, va de monte

a monte.

Desde los olivos, será un arco iris negro sobre la noche azul.

¡Ay!

Como un arco de viola, el grito ha hecho vibrar largas cuerdas del viento.

$$
\text { ¡Ay! }
$$

(Las gentes de las cuevas asoman sus velones) ¡Ay!

Texto poético: El grito 
LA GUITARRA

Empieza el llanto

de la guitarra.

Se rompen las copas

de la madrugada.

Empieza el llanto

de la guitarra.

Es inútil callarla.

Es imposible

callarla.

Llora monótona

como llora el agua,

como llora el viento

sobre la nevada

Es imposible

callarla,

Llora por cosas

lejanas.

Arena del Sur caliente

Llora flecha sin blanco,

la tarde sin mañana,

y el primer pájaro muerto

sobre la rama.

¡Oh guitarra!

Corazón malherido

por cinco espadas.

EL SILENCIO.

Oye, hijo mío, el silencio.

Es un silencio ondulado, un silencio,

donde resbalan valles y ecos

y que inclinan las frentes

hacia el suelo

Texto poético El silencio $\because$

Texto poético: La guitarra

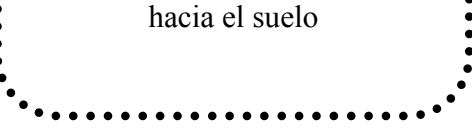

Objetivo: Conocer qué es una siguiriya. Ser conscientes de la presencia tan importante que para el poeta tienen los elementos musicales en esta obra.

Metodología: Leer los poemas "La guitarra", "El grito”, "El silencio", "El paso de la siguiriya" y "Después de pasar". De cada uno se extraerán las ideas 
fundamentales para que posteriormente, en parejas, los alumnos sean capaces de recoger los sonidos necesarios y ordenarlos adecuadamente, "componiendo" una breve siguiriya.

Materiales: Fotocopias proporcionadas por el docente con los poemas necesarios. Empleo de los ordenadores de la sala de informática del centro. Se necesitará la instalación de programas informáticos como Audacity o Sibelius, especializados en creación de sonidos. Para ello será necesaria la colaboración del profesor de música; creándose de este modo una actividad de carácter interdisciplinar.

Evaluación: Colaboración de_ambos alumnos. Además, han comprendido y "compuesto" correctamente una siguiriya.

\subsubsection{Actividad (2)}

Lee los poemas "La soleá" y "Saeta" de Lorca. A continuación, intenta explicar en qué pueden consistir dichas composiciones lírico-musicales. Después, busca información en las páginas webs que se citan, y con la información construye una definición ligada al ámbito literario y otra al musical.

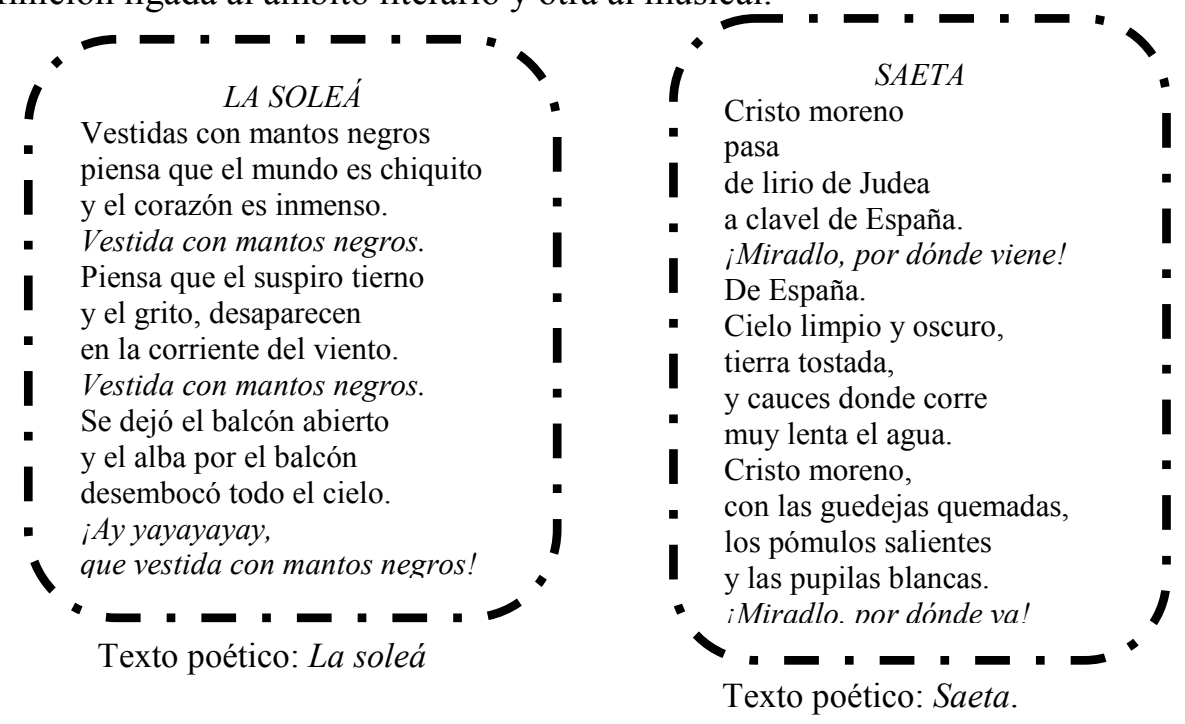

* http://hispanoteca.eu/Musik-Spanien/Flamenco/Cantes\%20flamencos.htm http://www.radiole.com/especiales/enciclopedia_flamenco/introduccion.html

Objetivo: Conocer en qué consiste una saeta y una soleá. Aprender la relación que música y literatura guardan en las definiciones que los especialistas manejan.

Metodología: Tras la lectura de ambos poemas, los alumnos deberán explicar las características de cada composición. A continuación, el profesor citará unas páginas web que los estudiantes visitarán con la finalidad de extraer información que sirva para complementar la que ellos habían dado y donde además puedan es- 
cuchar la interpretación de estas. Esta información la deberán separar en conceptos musicales o literarios.

Materiales: Fotocopias que el docente repartirá donde se incluirán ambos poemas y el aula de informática para buscar las páginas web.

Evaluación: El alumno/a entiende lo que es una saeta y una soleá; además, es capaz de diferenciar los conceptos literarios y musicales de cada una.

\subsubsection{Actividad (3)}

Se trata de que todos los miembros de la clase elaboréis una revista músicoliteraria. En este número de la revista se presentará el tema de la Petenera. Para ello, tras leer los poemas de Lorca sobre esta composición, os dividiréis en grupos y cada uno se encargará de una sección:

- Procedencia / historia de dicha composición.

- Posibles orígenes de su nombre.

- Características de la Petenera.

- Algunas composiciones e intérpretes conocidos.

Objetivos: Aprender la composición popular de la petenera. Trabajar conjuntamente en la creación de una revista.

Metodología: Cada grupo se encargará de recoger información sobre el punto que les haya tocado tratar. Cuando todos los grupos acaben, se juntará todo el material y se escogerá una portada que los alumnos pueden elaborar en la asignatura de Plástica y visual, en este caso, el departamento de dicha asignatura colaboraría con el departamento de Lengua y Literatura. Posteriormente, cada grupo expondrá al resto de la clase su parte de trabajo.

Materiales: La revista se creará de modo manual, por lo que todo material escolar será imprescindible.

Evaluación: El alumno es capaz de trabajar en equipo. Además, entiende la información y es capaz de explicar correctamente a sus compañeros aquello en lo que ha trabajado.

\subsubsection{Actividad (4)}

Muchos artistas del mundo de la música han escogido los versos de Lorca para componer sus canciones o, al menos, parte de ellas. Busca, en un artista, alguna canción en donde la letra corresponda a un poema perteneciente al Poema del cante jondo o al Romancero gitano de Lorca. Posteriormente, crea un CD con su libreto, el cual debe contener: una portada representativa del proyecto, una breve introducción sobre el poeta, el cantante y la relación entre ambos, y la letra del poema que el cantaor interpreta.

Objetivo: Conocer las influencias que se han producido: el flamenco en Lorca y Lorca en el flamenco 
Metodología: El profesor repartirá los artistas del mundo flamenco a los alumnos. Como tarea para casa deberán buscar alguna de las canciones en donde el cantaor interprete algún poema de Lorca y grabarla en un disco (el cual podrá ser dado por el docente). Además, también recogerán algunos datos de ese artista. Posteriormente en clase, crearán el libreto donde deben aparecer los elementos que se han señalado en el enunciado de la actividad.

Materiales: Un CD en blanco. Folios para la creación del libreto y material para su decoración como: rotuladores, tijeras, pegamento, imágenes... Todo depende de la creatividad del alumno.

Evaluación: El alumno/a presenta una ortografía adecuada. La información seleccionada está bien estructurada y elegida por lo que aporta los datos fundamentales entre la relación poeta - músico.

\subsubsection{Actividad (5) - Opcional -. Atención a la diversidad.}

Investiga sobre poetas de tu nación cuyos poemas hayan sido musicados por artistas del mismo país y transmítelo a tus compañeros.

Objetivo: Atender a la diversidad de alumnos extranjeros. Dar a conocer cómo cada nación tiene sus propios artistas influenciados por el folclore y cómo han influido ellos en este.

Metodología: Cada alumno extranjero, opcionalmente, buscará algún ejemplo de un músico de su nación que haya interpretado un poema de un escritor y lo mostrará en clase. Proporcionará además algunos datos del escritor (como el tipo de literatura que escribe) y los demás alumnos lo compararán con García Lorca, tanto en semejanzas como en diferencias.

Materiales: Los proporcionados por el alumno extranjero.

Evaluación: Se valorará positivamente la participación del alumno.

\section{CONCLUSIONES}

A lo largo del artículo se ha podido comprobar la importancia que la lírica popular tiene para uno de los escritores más universales de las letras españolas: Federico García Lorca. Como consecuencia, se ha producido una repercusión muy acusada en el mundo cultural. García Lorca ha servido de modelo a otros poetas, dando como resultado una propagación de esa lírica popular, o al menos un intento de producir composiciones alejadas de la vía culta impregnando sus páginas de elementos propios del pueblo. Pero no solo la literatura se ve afectada, sino que todas las artes pueden verse sometidas a dicha influencia, especialmente la música, en tanto que, la propia esencia poética lleva al ser humano a pensar en ritmo, melodía, armonía, etc. lo cual hace que sus puntos de unión sean muy cercanos.

Resulta lógico, entonces, asentar unas bases de conocimiento sobre esta lírica en los alumnos. En primer lugar, la propia literatura española se entendería mejor y cobraría otra perspectiva, ya que se habría formado una base en la que muchos escritores se han asentado a lo largo del tiempo. En segundo lugar, se conocería 
otro tipo de literatura, la cual no suele ser recogida o, al menos, muy estudiada por la Historia de la literatura y que, sin embargo, está implícita en ella. En tercer lugar, se abre toda una vía de educación social o cultural del país donde residen.

La educación no es solo enseñar contenidos, sino formar personas que viven dentro de un contexto, por lo que, es fundamental que este sea conocido por los estudiantes. Estos contenidos transversales son buscados muchas veces a través de otros elementos como actividades, textos de lectura específicos, etc. y, sin embargo, no suele pensarse que muchos de ellos se pueden hallar dentro de la propia historia literaria, en estas creaciones populares.

En relación con la importancia de crear nuevos métodos de enseñanza, es decir establecer innovaciones en el ámbito educativo, resulta imprescindible. La motivación se convierte en un factor fundamental para evitar el fracaso escolar. Por eso mismo, una de las metas que deben proponerse los profesores de Secundaria es que los alumnos sean capaces de sentir la motivación o gusto por aprender para evitar la reducción de contenidos que hoy día está teniendo lugar. Ello puede llevarse a cabo a partir de la mayor participación del alumnado, tanto en el centro como en las aulas; con técnicas que faciliten la comprensión o que, simplemente, sean capaces de atraer al estudiante; técnicas por las que los temarios no parezcan repetirse continuamente y se incluyan nuevos conceptos que tengan relevancia a la vez que atraigan la atención del adolescente.

En conclusión, la sociedad cambia y con ello el sistema educativo debe modernizarse y preparar a los jóvenes para la realidad actual, que en definitiva, es lo que los alumnos están demandando.

\section{REFERENCIAS BIBLIOGRÁFICAS}

CERRILLO TORREMOCHA, Pedro, C. (2003) "Hacia una didáctica del cancionero infantil: un nuevo marco para la recepción de la lírica popular infantil", en Intertextos: Aspectos sobre la recepción del discurso artístico. MENDOZA FILLOLA, Antonio, y CERRILLO TORREMOCHA, Pedro, C. (coord.). Cuenca, Ediciones de la Universidad de Castilla - La Mancha.

FUENTES, Tadea (1991). El folklore infantil en la obra de Federico García Lorca. Universidad de Granada.

GARCÍA LORCA, Federico (1994): Colección de Canciones Populares Españolas. Federico García Lorca, piano; La Argentinita, voz. Madrid: Sonifolk.

GARCÍA - POSADA, Miguel (ed.) (1994). Obras completas, Vol. I, (Prosa, 1). Madrid, Akal.

GRANDE, Félix (1992). García Lorca y el flamenco, Madrid, Mondadori

JOSEPHS, Allen y CABALLERO, Juan (eds.) (2009). Poema del Cante Jondo. Romancero gitano, Madrid, Cátedra [Col. Mil Letras].

MARTÍN, Eutimio (ed.) (1984). Federico García Lorca para niños. Madrid, Ediciones de la Torre. 
PEDRELL, Felipe (1922). Cancionero musical popular español. Valls, Eduardo Castells.

PRECIADO, Dionisio. (1969). Folklore español. Música, danza y ballet. Madrid, STVDIVM ediciones.

RODRÍGUEZ ROMERO, Domingo (ed.) (2010). Juego y teoría del duende. Barcelona, Nortesur. 